\title{
In-situ TEM Investigation of Solid Phase Transformations and Reactions
}

\author{
Klára Hajagos-Nagy ${ }^{1,2 *}$ \\ ${ }^{1}$ Centre for Energy Research, Eötvös Loránd Research Network, H-1121 Budapest, 29-33 Konkoly-Thege Miklós street, Hungary \\ 2 Department of Materials Science and Engineering, Faculty of Mechanical Engineering, Budapest University of Technology and \\ Economics, H-1111 Budapest, 7 Bertalan Lajos street, Hungary \\ * Corresponding author, e-mail: nagy.klara@energia.mta.hu
}

Received: 13 November 2020, Accepted: 10 April 2021, Published online: 01 July 2021

\begin{abstract}
In this paper, an example of phase analysis during annealing is presented using in-situ TEM. The example is demonstrated on amorphous $\mathrm{Cu}-\mathrm{Mn} / \mathrm{C}$ thin films focusing on phase identification in a multicomponent system. The transient states following the crystallization of the amorphous $\mathrm{Cu}-\mathrm{Mn}$ alloy and the reaction with the $\mathrm{C}$ substrate were analyzed by evaluating the diffraction patterns recorded at different temperatures. The camera constant was calibrated using the internal standard method. The change in composition of the $\mathrm{Cu}(\mathrm{Mn})$ solid solution was calculated by separating the effect of thermal expansion and solute concentration. Identification of the forming phases was aided by analyzing and comparing the probability of formation of all phases in the Cu-Mn-C-O system. After the crystallization of amorphous Cu-Mn alloy into $\mathrm{Cu}(\mathrm{Mn})$ and a-Mn-based solid solutions, the formation of the following carbide phases was observed: $\mathrm{Mn}_{23} \mathrm{C}_{6}, \mathrm{Mn}_{5} \mathrm{C}_{2}$ and $\mathrm{Mn}_{7} \mathrm{C}_{3}$.
\end{abstract}

Keywords

electron diffraction, in-situ TEM, phase analysis

\section{Introduction}

In-situ transmission electron microscopy (TEM) provides the opportunity to observe the dynamic response of a material to an externally applied stimulus as it happens inside the microscope. Based on the externally applied stimulus a broad class of in-situ TEM techniques exist, which include (but not limited to) annealing, nanoindentation, straining, electric and magnetic measurements, gas/solid and liquid/ solid interactions [1, 2]. In each of these areas the in-situ method allows us to discover transient states during chemical or structural transformations and/or correlate materials structure to their functionalities. The in-situ technique becomes extremely powerful when structural and morphological changes on nanoscale are the point of interest. The very broad range of microscopy techniques used in TEM investigations remains available also during in-situ measurements providing micro- and nanoscale information on the changes in morphology (using different imaging modes), crystal structure (electron diffraction and high-resolution electron microscopy), composition (energy dispersive spectroscopy) as well as chemical bonding (electron energy loss spectroscopy) of the investigated materials.
In particular, in-situ annealing benefits from the ability to observe the dynamics of phase transformations and reactions at high temperatures. Therefore, it is a widely used method for the investigation of solid phase transformations and reactions and grain growth during annealing [3-5].

In an in-situ experiment paying attention to a few aspects/ steps can make the measurement procedure and the evaluation of results more effective. However, these are hard to find in the literature. In this study, an example of phase analysis using in-situ annealing is presented. The goal is to give a description that can facilitate the in-situ investigation of phase transformations and reactions at high temperatures. The example is demonstrated on amorphous $\mathrm{Cu}-\mathrm{Mn} / \mathrm{C}$ thin films focusing on phase identification in a multicomponent system. Cu-Mn films are of recent technological interest due to their potential application as barrier layers in interconnect structures $[6,7]$. Previously, we reported the thermal stability and carbide formation in amorphous $\mathrm{Cu}-\mathrm{Mn} / \mathrm{C}$ films [8] focusing on the $\mathrm{Cu}-\mathrm{Mn}-\mathrm{C}-\mathrm{O}$ material's system and its interconnect application. In contrast, now the focus is on the methodological aspects using the $\mathrm{Cu}-\mathrm{Mn} / \mathrm{C}$ films as an example. 


\section{Experimental}

Amorphous $\mathrm{Cu}-\mathrm{Mn}$ alloy thin films were co-deposited in a high-vacuum direct current magnetron sputtering system. $50 \mathrm{~nm}$ thick films were grown on evaporated carbon foils. The carbon foils were prepared by thermal sublimation of a graphite rod on collodion film substrates supported by Ni grids in $1 \times 10^{-3} \mathrm{~Pa}$ pressure. The collodion films were then removed by annealing the grids at $400^{\circ} \mathrm{C}$ for $90 \mathrm{~min}$. The resulting carbon foils had an amorphous structure and a thickness of 10-20 nm which enables a direct planview TEM investigation without further sample preparation. The targets of $\mathrm{Cu}$ and $\mathrm{Mn}$ (of $99.99 \%$ and $99.95 \%$ purity, respectively) were mounted $25^{\circ}$ towards the vertical and the rotating substrate holder was positioned $12 \mathrm{~cm}$ from them. Prior to deposition, the sputtering chamber was evacuated to $5 \times 10^{-6} \mathrm{~Pa}$ base pressure and the substrates were annealed at $150{ }^{\circ} \mathrm{C}$ for $60 \mathrm{~min}$ to remove any mobile hydrocarbons. Then Ar (99.999 \% purity) was introduced to a pressure of $2 \times 10^{-1} \mathrm{~Pa}$. The targets were cleaned before deposition by pre-sputtering behind closed shutters for 5-10 min. The desired compositions (50 and $70 \mathrm{at} \% \mathrm{Mn}$ ) were reached by adjusting the power of magnetrons [9]. The substrate was kept at room temperature and the deposition rate of the layers was $0.4 \mathrm{~nm} / \mathrm{s}$. To minimize surface oxidation, the films were investigated immediately after deposition.

The films were in-situ annealed and examined by TEM in a Philips CM-20 electron microscope operated at $200 \mathrm{kV}$. The temperature range of in-situ annealing was $20-600{ }^{\circ} \mathrm{C}$. The temperature was increased in steps of $50{ }^{\circ} \mathrm{C}$ and at every stage the samples were held at the set temperature for $5 \mathrm{~min}$. The heating profile is shown in Fig. 1. The vacuum conditions during annealing were

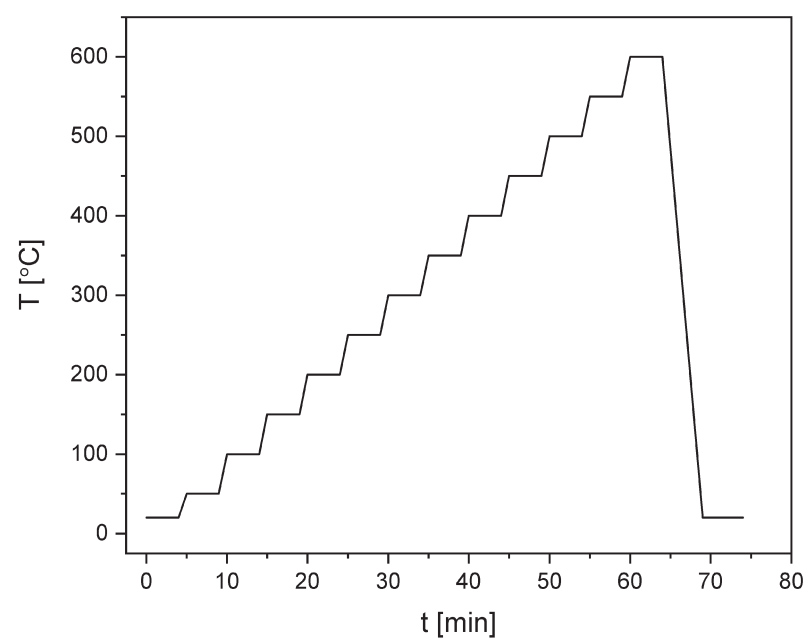

Fig. 1 Heating profile used in the in-situ experiments
$6 \times 10^{-5} \mathrm{~Pa}$ at $20{ }^{\circ} \mathrm{C}$, which increased to $1 \times 10^{-3} \mathrm{~Pa}$ at $600{ }^{\circ} \mathrm{C}$. The composition of the samples was verified using a NORAN energy dispersive spectrometer system with Ge detector attached to the CM-20 microscope. The structure and morphology was investigated by bright and dark field imaging and selected area electron diffraction (SAED). Separate samples were used in microscope and diffraction mode to be able to follow the initial area of observation during in-situ annealing. The phase compositions of the films were evaluated from SAED patterns using the Process Diffraction program [10]. The size of the area that contributed to SAED patterns measured $5 \mu \mathrm{m}$ in diameter.

\section{Results}

Figs. 2 and 3 demonstrate how in-situ TEM gives an overall look on the changes of structure and morphology during annealing. Fig. 2 shows the morphological changes in bright field TEM images and Fig. 3 shows the structural changes in SAED patterns of the films with Mn contents of 50 and 70 at $\%$. At both compositions the as-deposited films exhibit an overall homogeneous contrast in Fig. 2(a) and (i). In addition, a slight diffraction contrast is visible in the form of small black dots. The diffraction patterns (Fig. 3(a) and (i)) are composed of diffuse rings and slightly visible sharp rings. The diffuse rings originate from the amorphous $\mathrm{Cu}-\mathrm{Mn}$ phase [9], and the sharp rings originate from a fcc-type crystalline phase, which can be identified as $\mathrm{MnO}$ [9]. Mn oxidizes readily, even in ultra-high vacuum environment [11], and the $\mathrm{MnO}$ nanoparticles - which cause the slight diffraction contrast in Fig. 2(a) and (i) are located on the surface of the films. During annealing the two films exhibit similar behavior. With increasing temperature, the films remain amorphous below $300{ }^{\circ} \mathrm{C}$. At $300{ }^{\circ} \mathrm{C}$ both films crystallize, which is indicated by the sharpening of the diffuse diffraction rings in Fig. 3(c) and $(\mathrm{k})$. In addition to the rings of $\mathrm{MnO}$, the diffraction patterns are composed of an fcc- and a bcc-type crystalline phase. Considering the $\mathrm{Cu}-\mathrm{Mn}$ phase diagram [12] and our previous study of the $\mathrm{Cu}-\mathrm{Mn}$ thin film system [9], the two phases can be identified as $\mathrm{Cu}$-based solid solution (fcc) and $\alpha-\mathrm{Mn}$-based solid solution (bcc). The grain size of solid solutions is around 10-40 nm (Fig. 2(c) and (k)). While the $\mathrm{Cu}$-based solid solution remains stable up to $600{ }^{\circ} \mathrm{C}$, the Mn-based phases alter. The $\alpha$-Mn-based solid solution disappears at $400{ }^{\circ} \mathrm{C}$ and $450{ }^{\circ} \mathrm{C}$ in the films with Mn contents of 50 and 70 at $\%$, respectively. At $400{ }^{\circ} \mathrm{C}$ discontinuous diffraction rings appear indicating the formation of new phases (Fig. 3(e) and (m)). These rings can be 

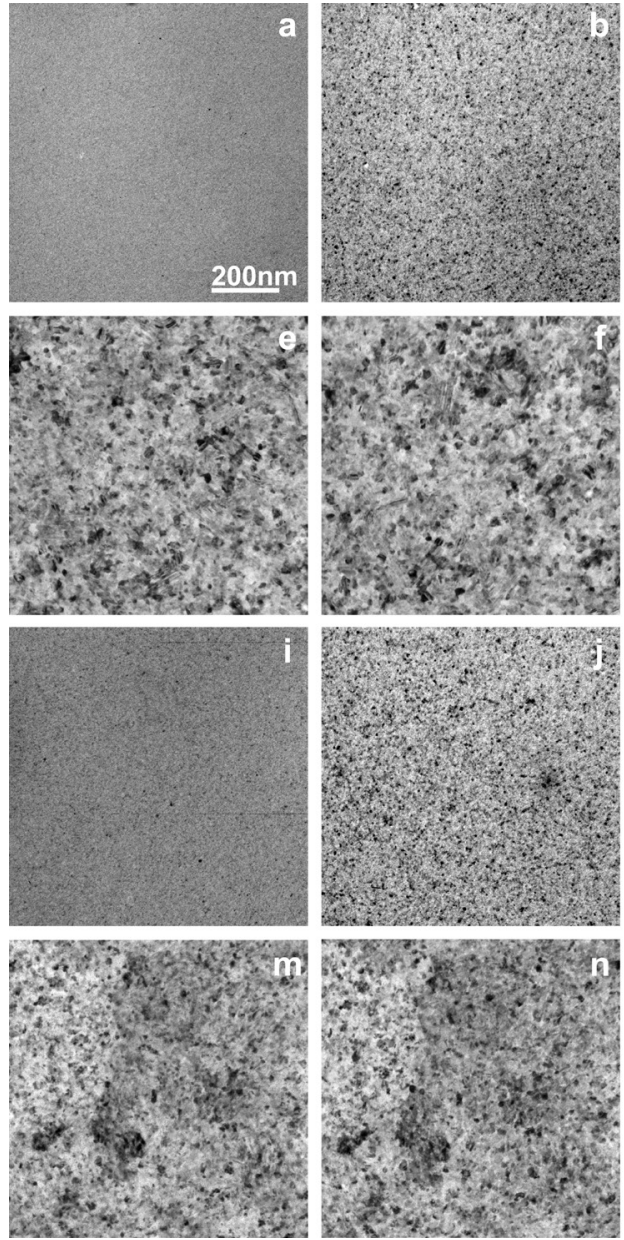
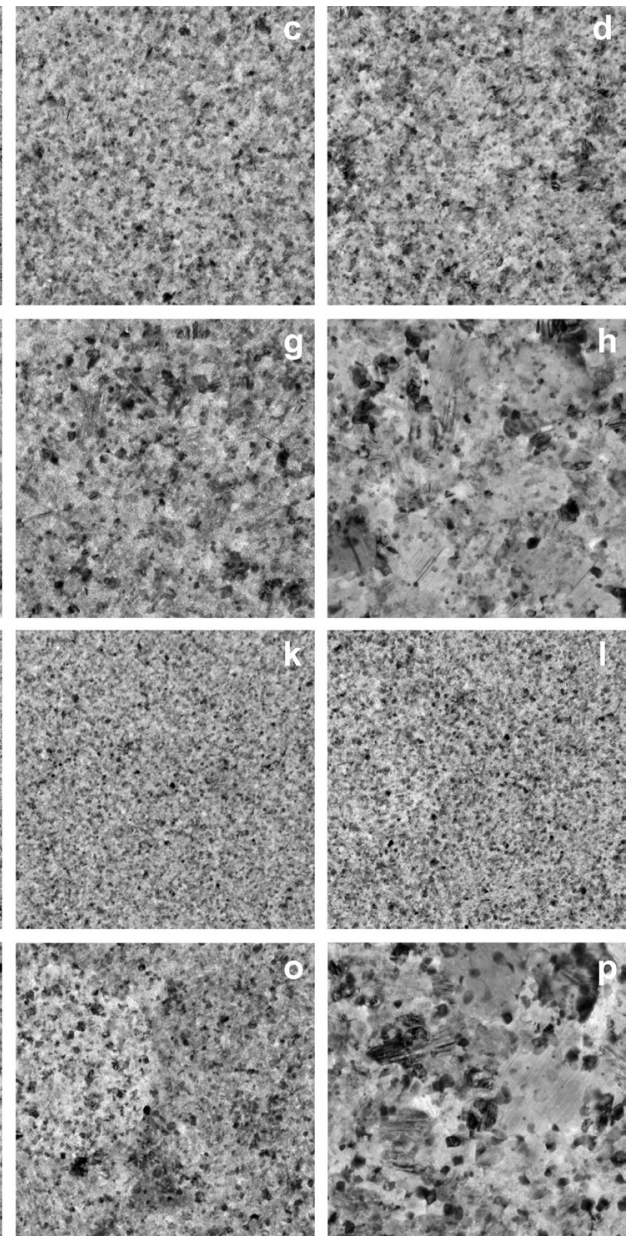

Fig. 2 Changes in the microstructure of the films with Mn contents of 50 at\% ((a)-(h)) and 70 at\% ((i)-(p)) during annealing in bright field TEM images ((a), (i) $20{ }^{\circ} \mathrm{C}$; (b), (j) $250{ }^{\circ} \mathrm{C}$; (c), (k) $300{ }^{\circ} \mathrm{C}$; (d), (1) $350{ }^{\circ} \mathrm{C}$; (e), (m) $400{ }^{\circ} \mathrm{C}$; (f), (n) $450{ }^{\circ} \mathrm{C},(\mathrm{g}),(\mathrm{o}) 500{ }^{\circ} \mathrm{C}$; (h), (p) $\left.600{ }^{\circ} \mathrm{C}\right)$

observed at each temperature up to $600{ }^{\circ} \mathrm{C}$ (Fig. 3(e)-(h) and $(m)-(p))$. For better view they are marked with quadrants on Fig. 4 (an enlarged version of Fig. 3(m)). In addition to the changes in phases, the intensity of surface oxidation increases with increasing temperature (Fig. 3(e)-(h) and (m)-(p)) and above $400{ }^{\circ} \mathrm{C}$ substantial grain growth can be observed (Fig. 2(e)-(h) and (m)-(p)).

To identify the new phases and to get more detailed information about the $\mathrm{Cu}$-based and $\alpha$-Mn-based solid solutions the camera constant must be known with high accuracy. For this purpose, the internal standard method was applied (shown in Fig. 5). This method allows to calibrate the camera constant for each annealing step and to increase the accuracy of the lattice parameter values by approximately one order of magnitude [13]. $\mathrm{MnO}$ was chosen as an internal standard (marked by triangles in Fig. 5) because $\mathrm{MnO}$ is present in the whole temperature range of annealing, most of its diffraction maxima can be easily separated from other phases and it produces stable and well defined diffraction rings without the risk of contamination, which is essential for the exact measurement of the position of diffraction maxima. For each temperature step, the $\mathrm{MnO}$ lattice parameter was calculated using Eq. (1):

$a_{T}=a_{T=20^{\circ} \mathrm{C}} \cdot(1+\alpha \cdot \Delta T)$,

where $a_{T}$ is the lattice parameter at a given temperature, $\alpha$ is the thermal expansion coefficient, and $T$ is the temperature. The thermal expansion coefficient for $\mathrm{MnO}$ was taken from the study of Suzuki et al. [14]. The resulting electron diffraction intensity distributions calibrated by the internal standard method are shown in Fig. 6. The diffraction maxima corresponding to the new phases are marked by arrows in Fig. 6. It must be noted that this calibration method can be used even if none of the phases present in the sample fits the requirements of an internal standard. In this case, a few $\mathrm{nm}$ thick one-component metal film should be evaporated onto the bottom side of the substrate [13]. This way the SAED patterns will be composed of the rings of the internal standard and studied material. Generally, nanocrystalline gold is used for this purpose [13]. 


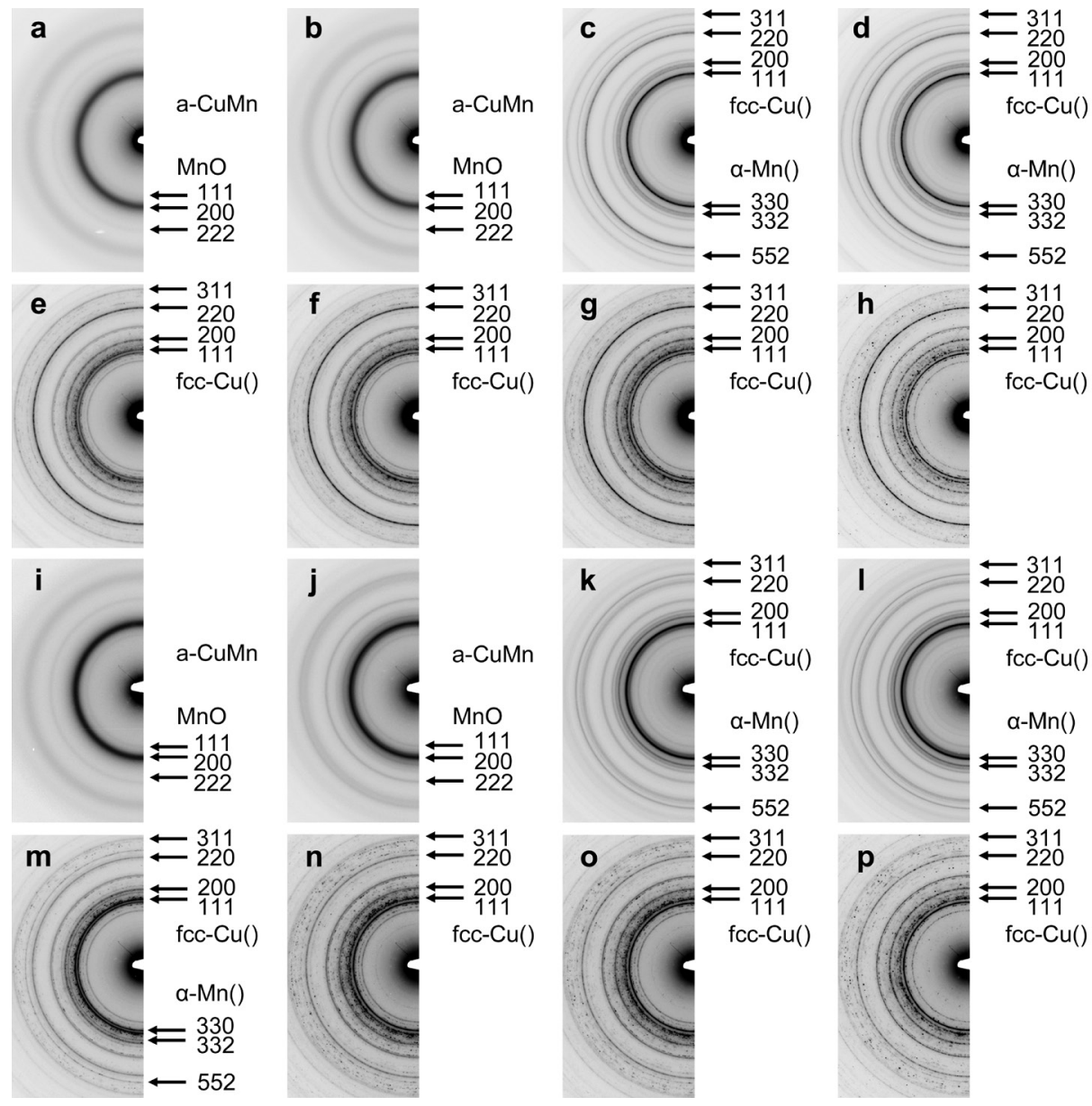

Fig. 3 SAED patterns of the films with Mn contents of 50 at $\%$ ((a)-(h)) and 70 at $\%$ ((i)-(p)) during annealing ((a), (i) $20^{\circ} \mathrm{C}$; (b), (j) $250^{\circ} \mathrm{C}$; (c), (k) $300{ }^{\circ} \mathrm{C}$; (d), (l) $350{ }^{\circ} \mathrm{C}$; (e), (m) $400{ }^{\circ} \mathrm{C}$; (f), (n) $450{ }^{\circ} \mathrm{C}$, (g), (o) $500{ }^{\circ} \mathrm{C}$; (h), (p) $600{ }^{\circ} \mathrm{C}$ )

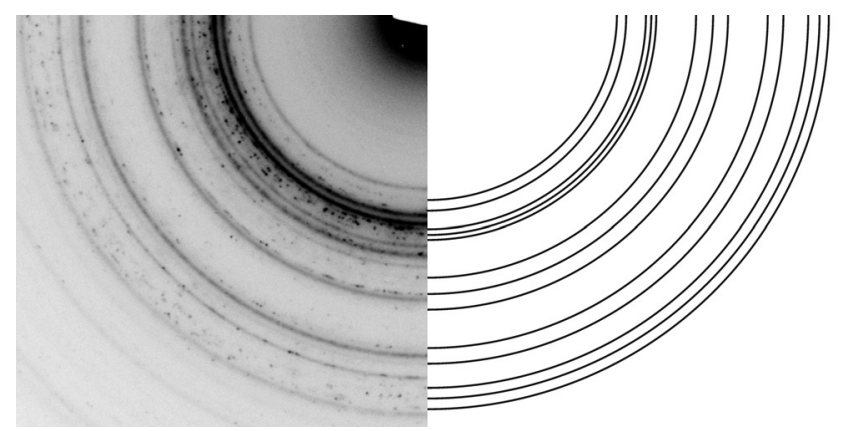

Fig. 4 SAED pattern obtained for the 70 at $\% \mathrm{Mn}$ film at $400{ }^{\circ} \mathrm{C}$. The quadrants denote the diffraction rings corresponding to the new phases

From the calibrated electron diffraction intensity distributions detailed information can be provided about the $\mathrm{Cu}$-based and $\alpha$-Mn-based solid solutions. In Fig. 6 the diffraction maxima of solid solutions continuously shift in both films, which indicates that their lattice parameters change during annealing. Fig. 7 shows the lattice parameters measured for $\mathrm{Cu}$-based and $\alpha$-Mn-based solid solutions in the temperature range of $300-600{ }^{\circ} \mathrm{C}$. In in-situ annealing experiments the change of lattice parameter can be caused by two mechanisms: thermal expansion and changes

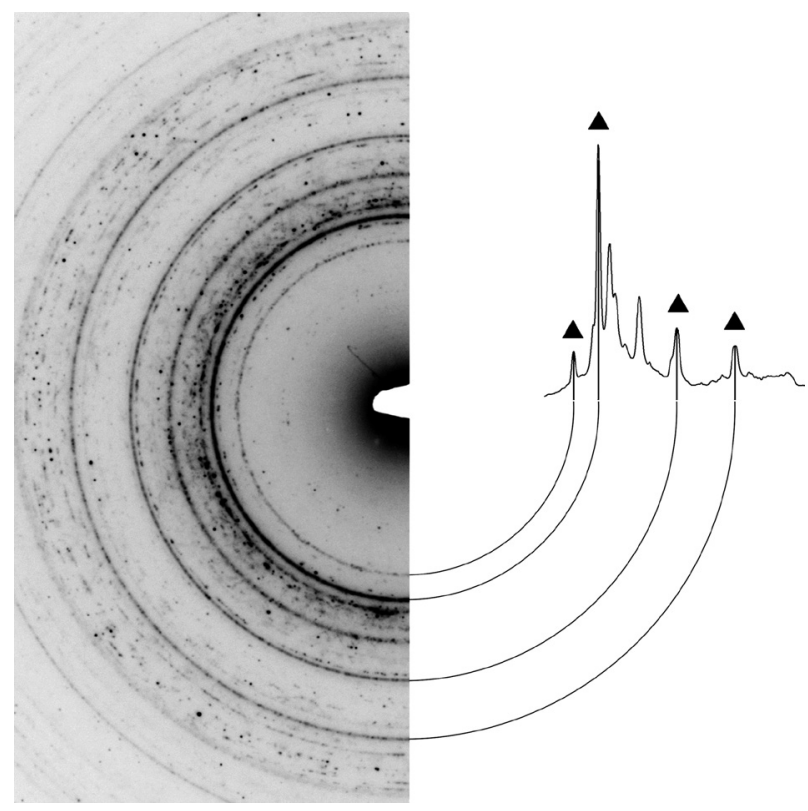

Fig. 5 The internal calibration of camera constant presented on the 70 at $\% \mathrm{Mn}$ film at $600{ }^{\circ} \mathrm{C}$. The quadrants denote the diffraction rings of the SAED pattern corresponding to the $\mathrm{MnO}$ phase, i.e. the internal standard. The triangles mark the MnO diffraction maxima on the electron diffraction intensity distribution 

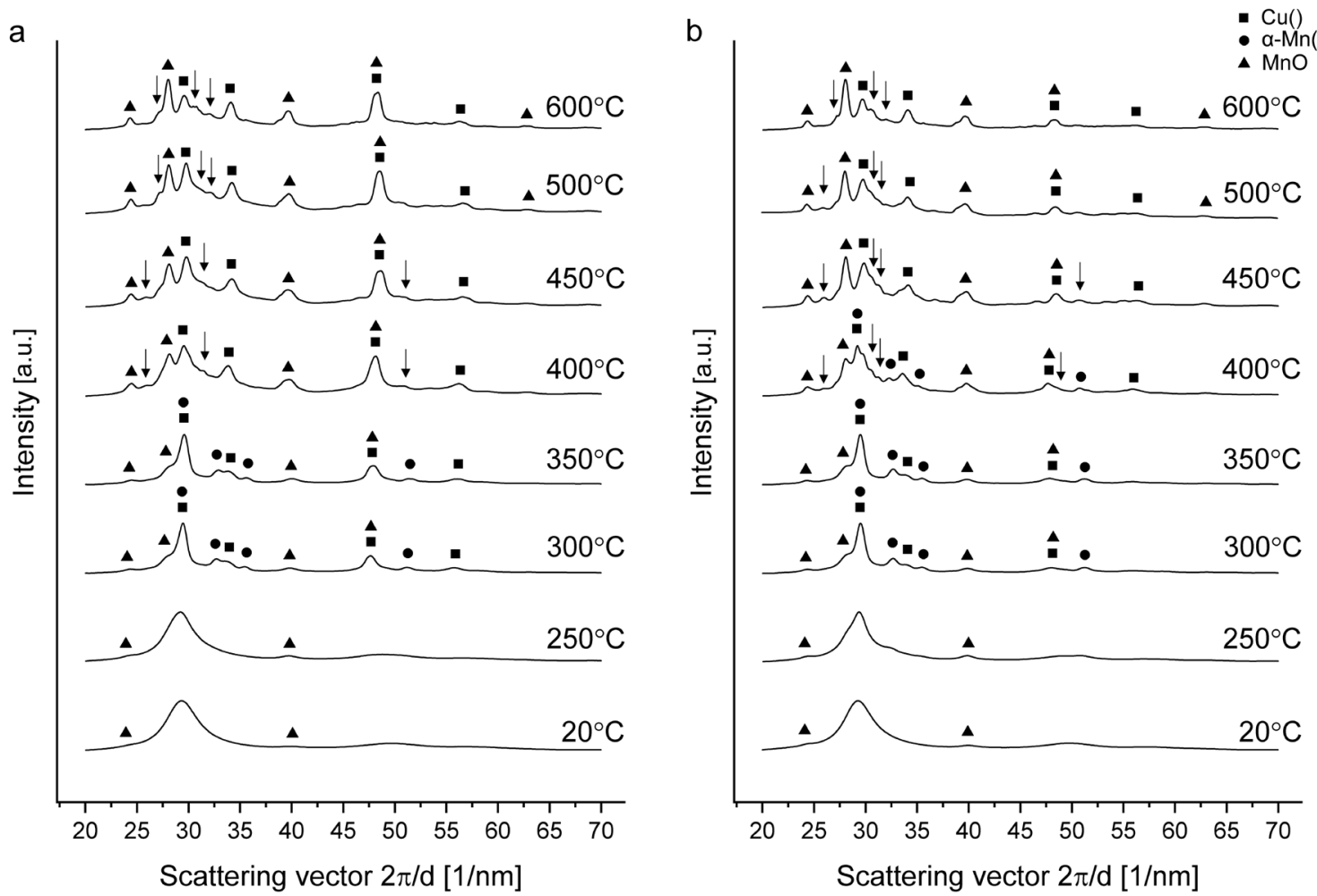

Fig. 6 (a) Electron diffraction intensity distributions for the films with Mn contents of 50 at\%; (b) and 70 at $\%$ at different temperatures during in-situ heat treatment

in solute concentration. By separating the effect of these mechanisms, the composition of solid solutions may be calculated. Thermal expansion can be calculated based on the lattice parameter for pure components at room temperature $\left(a_{C u}=3,6149 \AA\right.$ [15] and $a_{\alpha-M n}=8,9125 \AA$ [16]) and their thermal expansion coefficients $\left(a_{C u}=1.65 \times 10^{-5} 1 / \mathrm{K}[15]\right.$ and $\left.a_{M n}=2.17 \times 10^{-5} 1 / \mathrm{K}[16]\right)$ using Eq. (1). For comparison, the temperature dependence of pure lattice parameters is shown in Fig. 7 with dotted lines. The difference between the measured curves and the curves calculated for thermal expansion originates from the lattice distortions caused by solute atoms. To determine the composition of solid solutions, the dissolution limit of each possible solute element should be considered. $\alpha$-Mn can dissolve up to 10 at $\% \mathrm{Cu}$ under non-equilibrium conditions [9], $5 \mathrm{at} \%{ }^{\circ} \mathrm{C}$ in the temperature range of $0-400{ }^{\circ} \mathrm{C}[17]$, and a negligible amount of O [18]. Thus, the $\alpha-\mathrm{Mn}$-based solid solution can be composed of $\mathrm{Mn}, \mathrm{Cu}$ and $\mathrm{C}$ atoms. As it is not possible to separate the lattice distortions caused by substitutional $\mathrm{Cu}$ atoms and interstitional $\mathrm{C}$ atoms, we cannot calculate the composition of the $\alpha$-Mn-based solid solution and its changes in the temperature range of $300-400{ }^{\circ} \mathrm{C}$. By contrast, $\mathrm{Cu}$ can dissolve $20-45$ at $\% \mathrm{Mn}$ in the temperature range of 300$600{ }^{\circ} \mathrm{C}[12]$, and negligible amounts of $\mathrm{C}$ and $\mathrm{O}[19,20]$. Thus, the $\mathrm{Cu}$-based solid solution is composed of $\mathrm{Cu}$ and
$\mathrm{Mn}$ atoms, i.e. it is a $\mathrm{Cu}(\mathrm{Mn})$ solid solution and its composition can be calculated. Czigány et al. [21] measured the effect of composition on the $\mathrm{Cu}(\mathrm{Mn})$ lattice parameter as: $a=a_{C u}+0.322 c$, where $c$ is the Mn concentration in the $\mathrm{Cu}(\mathrm{Mn})$ solid solution in at $\%$. To consider the effect of thermal expansion we modified this equation as follows.

$a_{T}=a_{C u_{T}}+0.322 c$,

where $a_{C u_{T}}$ is calculated at each temperature using Eq. (1).

The Mn concentration calculated at each temperature is listed in Table 1. In both films the Mn content of the $\mathrm{Cu}(\mathrm{Mn})$ solid solution shows significant decline in the temperature range of $400-450{ }^{\circ} \mathrm{C}$.

The calibrated electron diffraction intensity distributions also allow to identify the new phases that appear at $400{ }^{\circ} \mathrm{C}$. First, a list of candidate phases is needed and phase identification will only confirm which of them corresponds to the diffraction intensity distributions. In the $\mathrm{Cu}-\mathrm{Mn}-\mathrm{C}-\mathrm{O}$ system in addition to the already identified phases oxide and carbide phases may form. Both $\mathrm{Cu}$ and Mn can form various oxide phases, but we can rule out some of them by comparing their probability of formation. Fig. 8(a) shows the standard free energy $\left(\Delta G^{0}\right)$ of $\mathrm{Cu}$ and $\mathrm{Mn}$ oxides in the temperature range of annealing. All Mn oxides have more negative free energies than the 

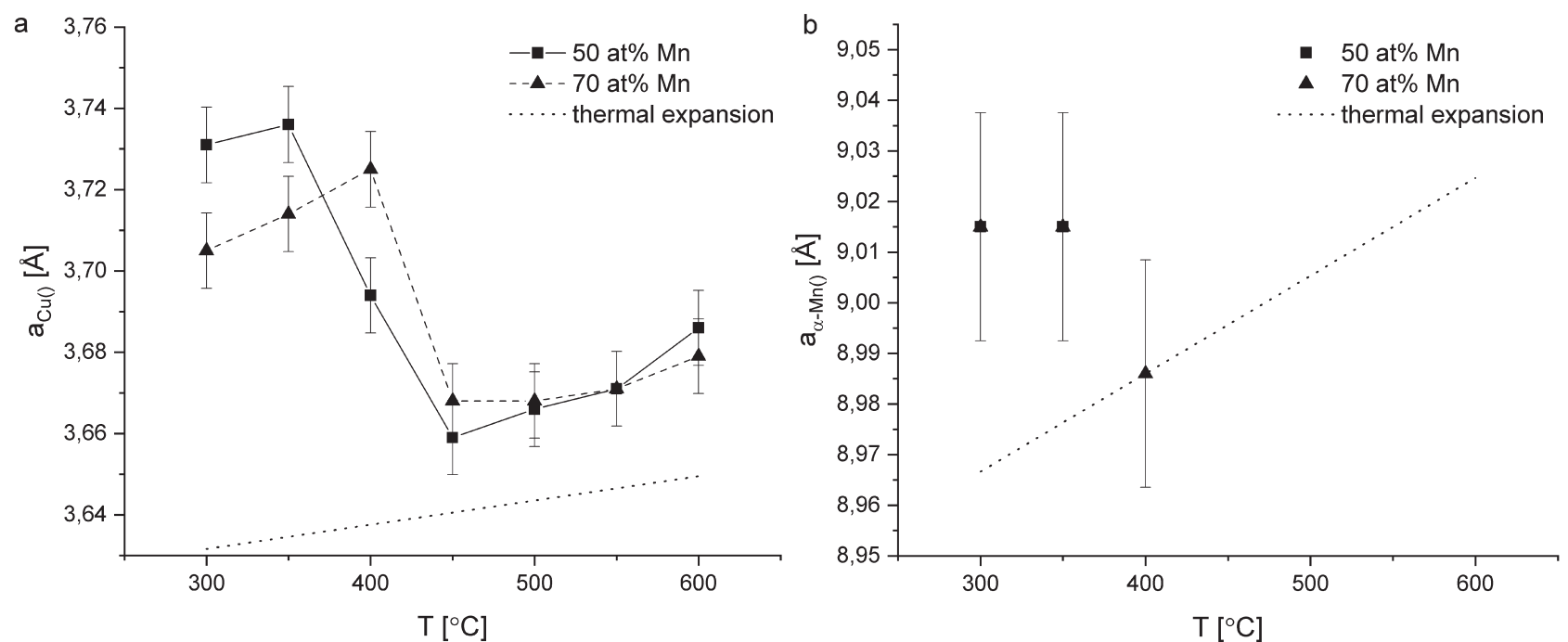

Fig. 7 (a) Lattice parameters measured for $\mathrm{Cu}$-based; (b) and $\alpha$-Mn-based solid solutions in the temperature range of $300-600{ }^{\circ} \mathrm{C}$

Table 1 Data used for calculating Mn concentration in the $\mathrm{Cu}(\mathrm{Mn})$ solid solution. The error of Mn concentration due to the error of lattice parameter measurement is $5 \%$.

\begin{tabular}{|c|c|c|c|c|c|}
\hline \multirow{2}{*}{$T\left[{ }^{\circ} \mathrm{C}\right]$} & \multirow{2}{*}{$a_{C u_{T}}[\AA]$} & $a_{T}[\AA]$ & $c[\mathrm{at} \%]$ & $a_{T}[\AA]$ & $c[\mathrm{at} \%]$ \\
\hline & & \multicolumn{2}{|c|}{50 at $\% \mathrm{Mn}$} & \multicolumn{2}{|c|}{70 at $\% \mathrm{Mn}$} \\
\hline 300 & 3.6316 & 3.731 & 31 & 3.705 & 23 \\
\hline 350 & 3.6346 & 3.736 & 31 & 3.714 & 25 \\
\hline 400 & 3.6376 & 3.694 & 18 & 3.725 & 27 \\
\hline 450 & 3.6405 & 3.659 & 6 & 3.668 & 9 \\
\hline 500 & 3.6435 & 3.666 & 7 & 3.668 & 8 \\
\hline 550 & 3.6465 & 3.671 & 8 & 3.671 & 8 \\
\hline 600 & 3.6495 & 3.686 & 11 & 3.679 & 9 \\
\hline
\end{tabular}

$\mathrm{Cu}$ ones at all temperatures. Thus, Mn oxidizes more readily than $\mathrm{Cu}$ and the formation of $\mathrm{Cu}$ oxides can be ruled out. From the four Mn oxides $\mathrm{MnO}$ has the most negative free energy. However, the stability of phases also depends on the concentration. To predict if another oxide can form alongside $\mathrm{MnO}$, we need to examine the $\mathrm{Mn}-\mathrm{O}$ phase diagram [18] (shown in Fig. 8(b)). The Mn-O phase diagram shows that up to 0.5 mole fraction of $\mathrm{O}$ two phases are in equilibrium: $\alpha-\mathrm{Mn}$ and $\mathrm{Mn}_{1-\mathrm{x}} \mathrm{O}$. In our case the $\mathrm{O}$ originates from the residual atmosphere in the microscope column $\left(1 \times 10^{-3} \mathrm{~Pa}\right.$ at $\left.600{ }^{\circ} \mathrm{C}\right)$, so the mole fraction of $\mathrm{O}$ is very low and only $\mathrm{MnO}$ can form. Considering carbides, $\mathrm{Cu}$ does not form carbide phases [19], but several Mn carbides exist [17] and Mn carbide formation is an expected reaction at the $\mathrm{Cu}-\mathrm{Mn} / \mathrm{C}$ interface. According to the $\mathrm{Mn}-\mathrm{C}$ phase diagram (Fig. 8(c)) three carbide phases can form in the temperature range of $20-600{ }^{\circ} \mathrm{C}$ depending on the concentration. The $\mathrm{C}$ substrate of our samples can be regarded as an infinite source of $\mathrm{C}$ atoms and $\mathrm{C}$

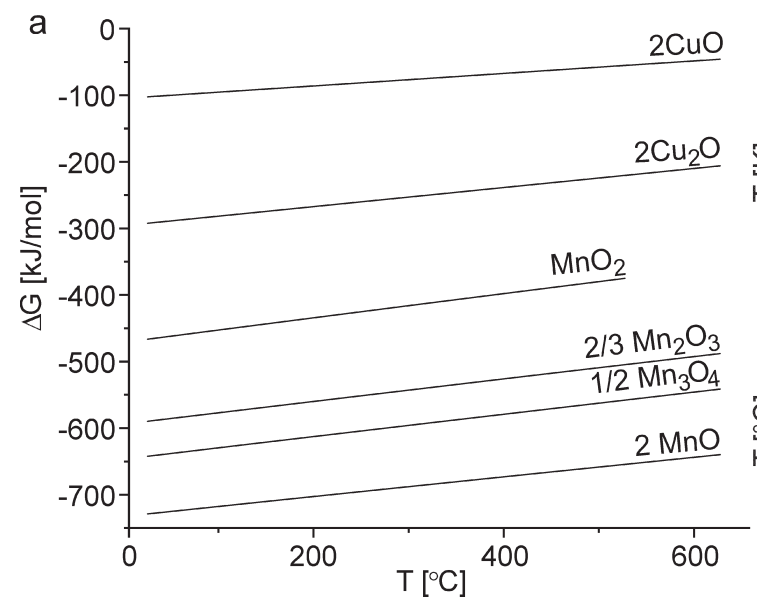

$b$

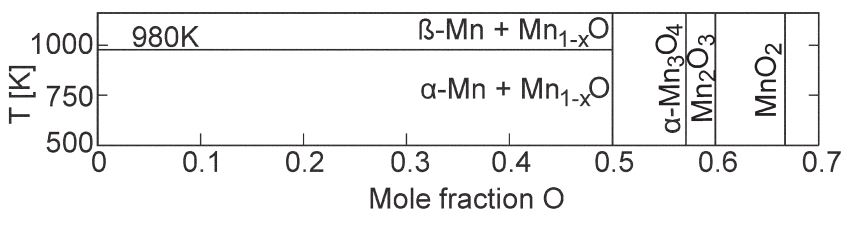

C

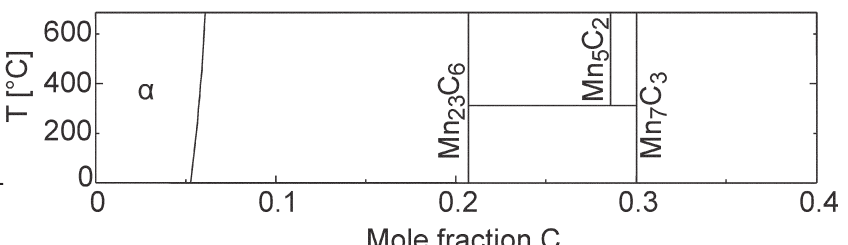

Fig. 8 Data used for creating a list of candidate phases to identify the phases forming in the temperature range of $400-600{ }^{\circ} \mathrm{C}$; (a) Standard free energies of $\mathrm{Cu}$ and $\mathrm{Mn}$ oxides in the temperature range of $20-600^{\circ} \mathrm{C}$. (All free energy values are normalized to $1 \mathrm{~mol} \mathrm{O}_{2}$.) [22-24]; (b) Mn-O equilibrium phase diagram in the temperature range of $227-927^{\circ} \mathrm{C}$ [18]; (c) Mn-C equilibrium phase diagram in the temperature range of 0-650 ${ }^{\circ} \mathrm{C}$ [17] 
diffusion into the $\mathrm{Cu}-\mathrm{Mn}$ films must be increasing with increasing temperature. Hence, the candidate phases are $\mathrm{Mn}_{23} \mathrm{C}_{6}, \mathrm{Mn}_{5} \mathrm{C}_{2}$ and $\mathrm{Mn}_{7} \mathrm{C}_{3}$ and are expected to appear in this consecutive order.

Fig. 9 shows enlargements of the diffraction intensity distributions (previously shown in Fig. 6) to highlight the formation of the new phases. In both films at $400{ }^{\circ} \mathrm{C}$ and $450{ }^{\circ} \mathrm{C}$ the markers of $\mathrm{Mn}_{23} \mathrm{C}_{6}$ and $\mathrm{Mn}_{5} \mathrm{C}_{2}$ fit all the unidentified markers and neither of them has a marker where no diffraction maxima exists. Hence below $500{ }^{\circ} \mathrm{C} \mathrm{Mn}_{23} \mathrm{C}_{6}$ and $\mathrm{Mn}_{5} \mathrm{C}_{2}$ carbides are found. Above $500{ }^{\circ} \mathrm{C} \mathrm{Mn} \mathrm{C}_{2}$ and $\mathrm{Mn}_{7} \mathrm{C}_{3}$ can be identified in both films. At $500{ }^{\circ} \mathrm{C}$ the two films behave differently. While in the film containing 50 at $\%$ Mn two carbides exist: $\mathrm{Mn}_{5} \mathrm{C}_{2}$ and $\mathrm{Mn}_{7} \mathrm{C}_{3}$, in the film containing 70 at $\% \mathrm{Mn}$ three carbides are in equilibrium: $\mathrm{Mn}_{23} \mathrm{C}_{6}, \mathrm{Mn}_{5} \mathrm{C}_{2}$ and $\mathrm{Mn}_{7} \mathrm{C}_{3}$. Having finished phase analysis one can conclude that our list of candidate phases proved to be correct. In addition, the phases appeared in the expected order with increasing temperature.

By summing up the presented results it becomes clear that a solid state reaction takes place between the $\mathrm{Cu}-\mathrm{Mn}$ film and the $\mathrm{C}$ substrate layer. $\mathrm{C}$ atoms diffuse into the film and at $400{ }^{\circ} \mathrm{C}$ they react with the metallic Mn present in the $\mathrm{Cu}(\mathrm{Mn})$ and the $\alpha$-Mn-based solid solutions. Hence, the $\mathrm{Mn}$ content of the $\mathrm{Cu}(\mathrm{Mn})$ phase drops, the $\alpha-\mathrm{Mn}$ phase disappears and carbide phases form. As the temperature increases further, more $\mathrm{C}$ diffuses into the film. Thus, the compound with a lower C:Mn ratio disappears $\left(\mathrm{Mn}_{23} \mathrm{C}_{6}\right)$ and a compound with a higher $\mathrm{C}: \mathrm{Mn}$ ratio forms $\left(\mathrm{Mn}_{7} \mathrm{C}_{3}\right)$.

\section{Conclusion}

In this work, I presented an effective technique for the evaluation of structural and compositional changes during in-situ TEM annealing demonstrated on $\mathrm{Cu}-\mathrm{Mn} / \mathrm{C}$ thin film system.

First, I presented how in-situ TEM gives an overall look on the changes of structure and morphology during annealing. From the overall look it could be determined that the amorphous $\mathrm{Cu}-\mathrm{Mn}$ films crystallized at $300{ }^{\circ} \mathrm{C}$ into $\mathrm{Cu}$-based and $\alpha$-Mn-based solid solutions. At $400{ }^{\circ} \mathrm{C}$ new phases appeared accompanied with disappearance of the $\alpha$-Mn-based solid solution. Above $400{ }^{\circ} \mathrm{C}$ intensive surface oxidation and substantial grain growth took place.

Second, by using the internal standard method for the calibration of camera constant the transient states after crystallization and the reaction with the $\mathrm{C}$ substrate could be analyzed. By separating the effect of thermal expansion and changes in solute concentration, the composition of the $\mathrm{Cu}(\mathrm{Mn})$ solid solution in the temperature range of $300-600{ }^{\circ} \mathrm{C}$ was calculated. To identify the new phases that appear at $400^{\circ} \mathrm{C}$, a list of candidate phases was made
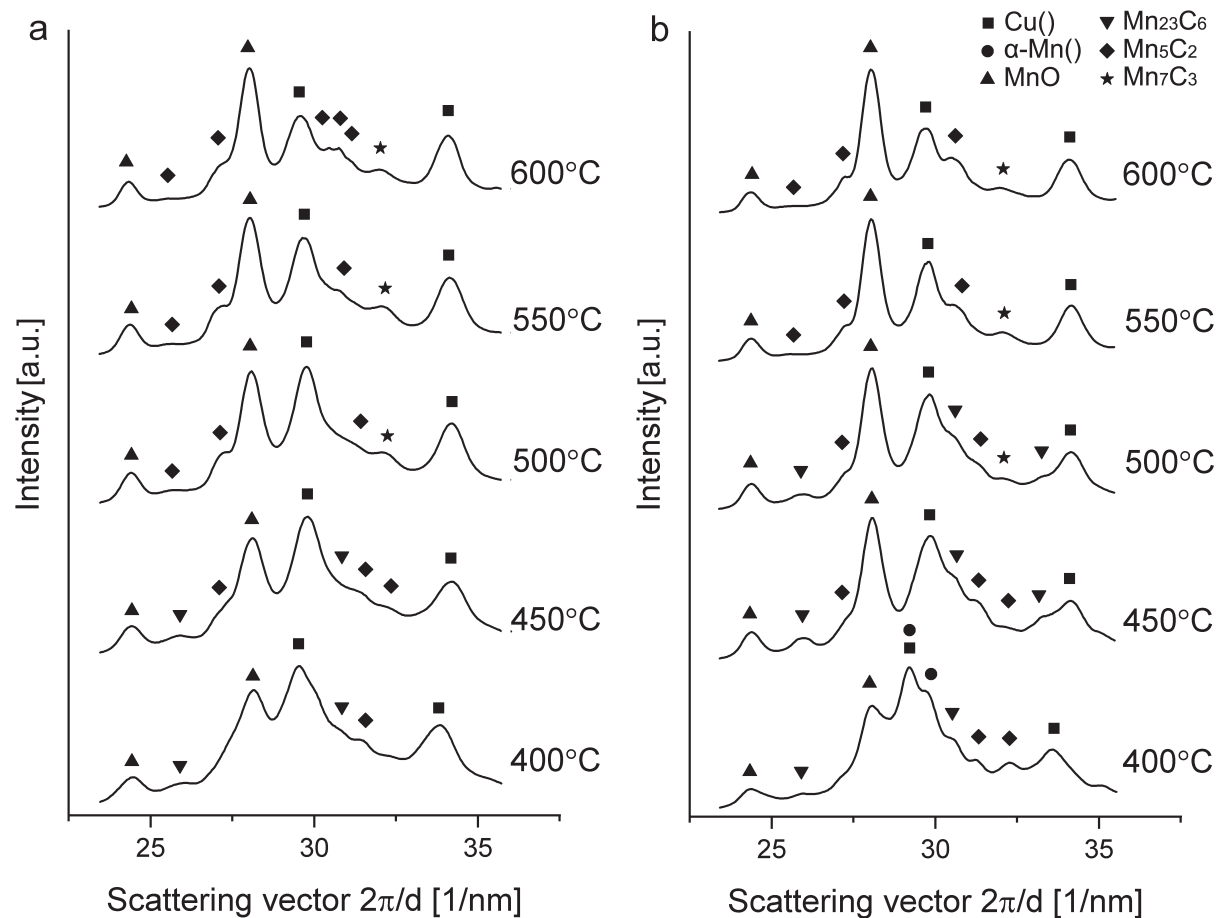

Fig. 9 (a) Electron diffraction intensity distributions determined for the films with Mn contents of 50 at $\%$; (b) and 70 at $\%$, highlighting carbide formation 
by comparing the probability of formation of all phases in the $\mathrm{Cu}-\mathrm{Mn}-\mathrm{C}-\mathrm{O}$ multicomponent system. Phase identification confirmed the candidate phases: $\mathrm{Mn}_{23} \mathrm{C}_{6}$ and $\mathrm{Mn}_{5} \mathrm{C}_{2}$ carbides were present in the temperature range of 400-500 ${ }^{\circ} \mathrm{C}$, and $\mathrm{Mn}_{5} \mathrm{C}_{2}$ and $\mathrm{Mn}_{7} \mathrm{C}_{3}$ carbides from $500{ }^{\circ} \mathrm{C}$ to $600{ }^{\circ} \mathrm{C}$. The presented example can serve as a guideline for the in-situ investigation of phase transformations and reactions at high temperatures.

\section{References}

[1] Ferreira, P. J., Mitsuishi, K., Stach, E. A. "In Situ Transmission Electron Microscopy", MRS Bulletin, 33(2), pp. 83-90, 2008. https://doi.org/10.1557/mrs2008.20

[2] Taheri, M. L., Stach, E. A., Arslan, I., Crozier, P. A., Kabius, B. C., LaGrange, T., Minor, A. M., Takeda, S., Tanase, M., Wagner, J. B., Sharma, R. "Current status and future directions for in situ transmission electron microscopy", Ultramicroscopy, 170, pp. 86-95, 2016. https://doi.org/10.1016/j.ultramic.2016.08.007

[3] Saka, H., Kamino, T., Arai, S., Sasaki K. "In Situ Heating Transmission Electron Microscopy", MRS Bulletin, 33(2), pp. 93-100, 2008.

https://doi.org/10.1557/mrs2008.21

[4] Simões, S., Calinas, R., Vieira, M. T., Vieira, M. F., Ferreira, P. J. "In situ TEM study of grain growth in nanocrystalline copper thin films", Nanotechnology, 21(14), Article number: 145701, 2010. https://doi.org/10.1088/0957-4484/21/14/145701

[5] Malladi, S. K., Xu, Q., Van Huis, M. A., Tichelaar, F. D., Batenburg, K. J., Yücelen, E., Dubiel, B., Czyrska-Filemonowicz, A., Zandbergen, H. W. "Real-Time Atomic Scale Imaging of Nanostructural Evolution in Aluminum Alloys", Nano Letters, 14(1), pp. 384-389, 2014.

https://doi.org/10.1021/n1404565j

[6] Koike, J., Wada, M. "Self-forming diffusion barrier layer in $\mathrm{Cu}-$ Mn alloy metallization", Applied Physics Letters, 87(4), Article number: 041911, 2005.

https://doi.org/10.1063/1.1993759

[7] Bogan, J., Lundy, R., McCoy, A. P., O’Connor, R., Byrne, C., Walsh, L., Casey, P., Hughes, G. "In-situ surface and interface study of atomic oxygen modified carbon containing porous low- $\kappa$ dielectric films for barrier layer applications", Journal of Applied Physics, 120(10), Article number: 105305, 2016.

https://doi.org/10.1063/1.4962371

[8] Nagy, K. H., Misják, F. "In-situ transmission electron microscopy study of thermal stability and carbide formation in amorphous $\mathrm{Cu}-\mathrm{Mn} / \mathrm{C}$ films for interconnect application", Journal of Physics and Chemistry of Solids, 121, pp. 312-318, 2018. https://doi.org/10.1016/j.jpcs.2018.05.036

[9] Misják, F., Nagy, K. H., Lobotka, P., Radnóczi, G. "Electron scattering mechanisms in $\mathrm{Cu}-\mathrm{Mn}$ films for interconnect applications", Journal of Applied Physics, 116(8), Article number: 083507, 2014. https://doi.org/10.1063/1.4893718

\section{Acknowledgement}

The author thanks Prof. György Radnóczi, Prof. Péter János Szabó and Dr. Fanni Misják for valuable discussions. This study was supported by the Hungarian Academy of Sciences (Grant Nos. NN OTKA 112156 and OTKA 81808 ) and by the NRDI Fund (TKP2020 IES, Grant No. BME-IE-NAT) based on the charter of bolster issued by the NRDI Office under the auspices of the Ministry for Innovation and Technology.

[10] Lábár, J. L. "Consistent indexing of a (set of) single crystal SAED pattern(s) with the ProcessDiffraction program", Ultramicroscopy, 103(3), pp. 237-249, 2005.

https://doi.org/10.1016/j.ultramic.2004.12.004

[11] McCoy, A. P., Bogan, J., Walsh, L., Byrne, C., O'Connor, R., Woicik, J. C., Hughes, G. "The impact of porosity on the formation of manganese based copper diffusion barrier layers on low$\kappa$ dielectric materials", Journal of Physics D: Applied Physics, 48(32), Article number: 325102, 2015.

https://doi.org/10.1088/0022-3727/48/32/325102

[12] Wang, C. P., Liu, X. J., Ohnuma, I., Kainuma, R., Ishida, K. "Thermodynamic assessments of the $\mathrm{Cu}-\mathrm{Mn}-\mathrm{X}(\mathrm{X}: \mathrm{Fe}, \mathrm{Co})$ systems", Journal of Alloys and Compounds, 438(1-2), pp. 129-141, 2007. https://doi.org/10.1016/j.jallcom.2006.08.018

[13] Kovács Kis, V., Czigány, Z., Németh, T. "Nanostructural investigation of slightly altered rhyolitic volcanic glass", Materials Characterization, 127, pp. 121-128, 2017. https://doi.org/10.1016/J.MATCHAR.2017.02.019

[14] Suzuki, I., Okajima, S., Seya, K. "Thermal expansion of singlecrystal manganosite", Journal of Physics of the Earth, 27(1), pp. 63-69, 1979. https://doi.org/10.4294/jpe1952.27.63

[15] Gray, T., Mann, N., Whitby, M. "Technical data for Copper", [online] Available at: http://periodictable.com/Elements/029/data. html [Accessed: 14 April 2021]

[16] Gray, T., Mann, N., Whitby, M. "Technical data for Manganese", [online] Available at: http://periodictable.com/Elements/025/data. html [Accessed: 14 April 2021]

[17] Paek, M. K., Pak, J. J., Kang, Y. B. "Phase equilibria and thermodynamics of $\mathrm{Mn}-\mathrm{C}, \mathrm{Mn}-\mathrm{Si}, \mathrm{Si}-\mathrm{C}$ binary systems and $\mathrm{Mn}-\mathrm{Si}-\mathrm{C}$ ternary system by critical evaluation, combined with experiment and thermodynamic modeling", Calphad, 46, pp. 92-102, 2014. https://doi.org/10.1016/j.calphad.2014.02.007

[18] Grundy, A. N., Hallstedt, B., Gauckler, L. J. "Assessment of the Mn-O system", Journal of Phase Equilibria, 24(1), pp. 21-39, 2003. https://doi.org/10.1007/s11669-003-0004-6

[19] Centre for Research in Computational Thermochemistry "C-Cu phase diagram", [online] Available at: http://www.crct.polymtl. $\mathrm{ca} /$ fact/phase_diagram.php?file $=\mathrm{C}-\mathrm{Cu}$.jpg $\&$ dir $=$ S GTE2014 [Accessed 14 April 2021] 
[20] Schramm, L., Behr, G., Löser, W., Wetzig, K. "Thermodynamic reassessment of the $\mathrm{Cu}-\mathrm{O}$ phase diagram", Journal of Phase Equilibria and Diffusion, 26(6), pp. 605-612, 2005. https://doi.org/10.1007/s11669-005-0005-8

[21] Czigány, Z., Misják, F., Geszti, O., Radnóczi, G. "Structure and phase formation in $\mathrm{Cu}-\mathrm{Mn}$ alloy thin films deposited at room temperature", Acta Materialia, 60(20), pp. 7226-7231, 2012. https://doi.org/10.1016/j.actamat.2012.09.034

[22] Jacob, K. T., Shekhar, C., Li, X., Kale, G. M. "Gibbs energy of formation of $\mathrm{CaCu} 3 \mathrm{Ti} 4 \mathrm{O} 12$ and phase relations in the system $\mathrm{CaO}-$ CuO/Cu2O-TiO2", Acta Materialia, 56(17), pp. 4798-4803, 2008. http://dx.doi.org/10.1016/j.actamat.2008.05.038
[23] Jacob, K. T., Kumar, A., Waseda, Y. "Gibbs Energy of Formation of MnO: Measurement and Assessment", Journal of Phase Equilibria and Diffusion, 29(3), pp. 222-230, 2008.

https://doi.org/10.1007/s11669-008-9280-5

[24] Jacob, K. T., Kumar, A., Rajitha, G., Waseda, Y. "Thermodynamic Data for Mn3O4, Mn2O3 and MnO2", High Temperature Materials and Processes, 30(4), pp. 459-472, 2011.

https://doi.org/10.1515/htmp.2011.069 